\title{
MMP12 knockout prevents weight and muscle loss in tumor-bearing mice
}

Lingbi Jiang ${ }^{1}$, Mingming Yang ${ }^{1,2}$, Shihui $\mathrm{He}^{1}$, Zhengyang $\mathrm{Li}^{1}$, Haobin $\mathrm{Li}^{1}$, Ting $\mathrm{Niu}^{1}$, Dehuan $\mathrm{Xie}^{2}$, Yan $\mathrm{Mei}^{2}$, Xiaodong He ${ }^{1}$, Lili Wei ${ }^{3}$, Pinzhu Huang ${ }^{3}$, Mingzhe Huang ${ }^{3}$, Rongxin Zhang ${ }^{1,4}$, Lijing Wang ${ }^{1 *}$ and Jiangchao $\mathrm{Li}^{i^{*}} \mathrm{C}$

\begin{abstract}
Background: Colorectal cancer is a malignant gastrointestinal cancer, in which some advanced patients would develop cancer cachexia (CAC). CAC is defined as a multi-factorial syndrome characterized by weight loss and muscle loss (with or without fat mass), leading to progressive dysfunction, thereby increasing morbidity and mortality. $\mathrm{Apc}^{\mathrm{Min} /+}$ mice develop spontaneous intestinal adenoma, which provides an established model of colorectal cancer for CAC study. Upon studying the Apc $\mathrm{Min} /+^{+}$mouse model, we observed a marked decrease in weight gain beginning

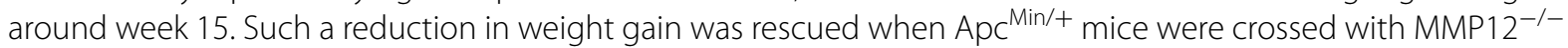
mice, indicating that MMP12 has a role in age-related $\mathrm{ApC}^{\mathrm{Min} /+}$-associated weight loss. As a control, the weight of MMP12 $2^{-/}$mice on a weekly basis, their weight were not significantly different from those of WT mice.

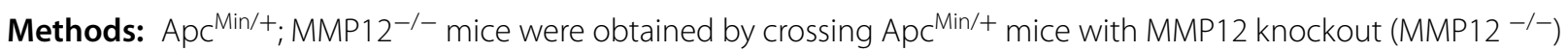
mice. Histological scores were assessed using hematoxylin-eosin (H\&E) staining. MMP12 expression was confirmed by immunohistochemistry and immunofluorescence staining. ELISA, protein microarrays and quantitative Polymerase Chain Reaction (qPCR) were used to investigate whether tumor could up-regulate IL-6. Cell-based assays and western blot were used to verify the regulatory relationship between IL-6 and MMP12. Fluorescence intensity was measured to determine whether MMP12 is associated with insulin and insulin-like growth factor 1 (IGF-1) in vitro. MMP12 inhibitors were used to explore whether MMP12 could affect the body weight of $\mathrm{Apc}^{\mathrm{Min} /+}$ mice.
\end{abstract}

Results: MMP12 knockout led to weight gain and expansion of muscle fiber cross-sectional area (all mice had C57BL/6 background) in Apc ${ }^{\mathrm{Min} /+}$ mice, while inhibiting MMP12 could suppress weight loss in Apc ${ }^{\mathrm{Min} /+}$ mice. MMP12 was up-regulated in muscle tissues and peritoneal macrophages of Apc ${ }^{\mathrm{Min} /+}$ mice. IL-6 in tumor cells and colorectal cancer patients is up-regulation. IL-6 stimulated MMP12 secretion of macrophage.

Conclusions: MMP12 is essential for controlling body weight of Apc Min/+ mice. Our study shows that it exists the crosstalk between cancer cells and macrophages in muscle tissues that tumor cells secrete IL-6 inducing macrophages to up-regulate MMP12. This study may provide a new perspective of MMP12 in the treatment for weight loss induced by CAC.

Keywords: MMP12, Apc ${ }^{\mathrm{Min} /+}$, Macrophage, IL-6, Cancer cachexia, Colorectal cancer

*Correspondence: wanglijing@gdpu.edu.cn; lijiangchao1234@163.com ${ }^{1}$ Institute of Basic Medical Sciences, School of Life Sciences and Biopharmaceuticals, Guangdong Pharmaceutical University, No. 280 Waihuan Rd. E, Higher Education Mega Center, Guangzhou 510006, China Full list of author information is available at the end of the article

\section{Background}

Colorectal cancer (CRC) is the third most common malignant tumor in the worldwide in 2020, with poor prognosis and low survival rate, which seriously affects life quality of patients [1-4]. With CRC, $50-61 \%$ of 
patients developed cancer cachexia (CAC). However, $\mathrm{CAC}$ remains clinically underemphasized, and its underlying mechanism is not yet fully understood. Previous studies suggest that $\mathrm{CAC}$ is, to some extent, related to the local and systemic tumor immune responses and metabolic disorders [5].

Clinically, ongoing loss of body weight and skeletal muscle mass is a late outcome of nearly $80 \%$ of patients with different types of cancer, including pancreatic cancer, esophageal cancer, gastric cancer, lung cancer, liver cancer and $\mathrm{CRC}$, and the mortality rate is as high as $30 \%$ [6-8]. More attention has been paid to CAC in recent years, and great progress has been made in the diagnosis and treatment of CRC $[1,9]$. A standard treatment of CRC is a combination of surgery, chemotherapy and radiotherapy, but it fails to significantly reduce mortality rate, which is closely related to CAC syndrome in patients with advanced CRC [10].

Cancer cachexia is mainly characterized by weight loss. This syndrome is multifactorial, there are a complex interaction of tumor and host factors. Weight loss in patients include the loss of both adipose tissue and skeletal muscle mass, weight loss is mainly from the fat and the muscle. The Apc ${ }^{\mathrm{Min} /+}$ mouse is accepted as an established model of colorectal cancer and cachexia [11, 12]. This mouse model with cachexia is the gradual progression of tumor development and muscle wasting that is more physiologically related to human disease, compared to tumor implant models.

MMP12, a matrix metalloprotease, also known as macrophage metalloelastase, belongs to the endoproteolytic enzyme family. Its activity is dependent on metal ions such as calcium and zinc, and it can degrade extracellular matrix. MMP12 was discovered in the morphological development of tadpoles. It is mainly derived from macrophages and is required for recruitment of monocytes [13-16]. MMP12 affects adipose tissue dilatation, the number of macrophages, body weight and body fat in MMP12-knockout mice fed with high fat diet [13]. Previous studies reported that MMP12 could specifically degrade insulin [17]. Researchers at the University of Washington confirmed that MMP12 regulates insulin sensitivity and is positively correlated with insulin resistance [18]. MMP12 was further identified as a therapeutic target for insulin-related metabolic diseases $[13,18]$. Insulin plays an important role in disorders of glucose and lipid metabolism (e.g. impaired glucose tolerance and insulin resistance) are associated with body weight loss induced by CAC [19].

Some inflammatory cytokines, interleukin 6 (IL-6), monocyte chemoattractant protein-1 (MCP-1), tumor necrosis factor (TNF) and zinc- $\alpha 2$-glycoprotein (AZGP1) and pancreatic enzymes have been shown to be related to
CAC [14, 20-23]. Clinical evidence had shown that IL-6 in tumor biopsy tissue is an inflammatory marker in the diagnosis of CAC, and high levels of IL-6 in tumor tissue and serum correlate with weight loss and muscle atrophy $[24,25]$. IL-6 is a pleiotropic proinflammatory cytokine secreted by normal monocytes, fibroblasts, endothelial cells, Th2 cells and vascular endothelial cells. A variety of tumor cells also secrete IL-6 [14, 20, 26], which can target macrophages to regulate the tumor microenvironment $[14,27]$. CAC is a classic metabolic syndrome of type 2 diabetes with insulin resistance, and muscular dystrophy is a hallmark of CAC [28]. In addition, over-expression of IL-6 aggravates weight loss of cancer cachexia in $\mathrm{Apc}^{\mathrm{Min} /+}$ mice, whereas increased knockout of IL-6 reverses that [29]. Multiple studies have suggested that IL-6 leads to insulin resistance and promotes muscle atrophy, as skeletal muscle is the main tissue in which insulin stimulates glucose uptake [30-32]. In short, various studies have proven that IL-6 can induce insulin resistance, and as a consequence indirectly exacerbates muscle loss in CAC.

In our study, the data shows that the crosstalk between cancer cells and macrophages in muscle tissues is that tumor cells secrete IL-6 inducing macrophages to upregulate MMP12. It may provide a new point view of MMP12 function in weight loss induced by CAC.

\section{Methods}

\section{Mice}

B6.129X-MMP12tm1Sds/J macrophage metalloelastasedeficient (MMP12 $2^{-I-}$ ) mice, with a C57BL/6 background were purchased from The Jackson Laboratory, USA (No.T001457, https://www.jax.org/strain/004855). All $\mathrm{Apc}^{\mathrm{Min} /+}$ mice (No. T001457) were obtained from Gem Pharmatech, China (No. 004855, http://www.gemph armatech.com/cn/index.php/searchinfo/59/17.html). Wild-type (WT/C57BL/6J) mice were purchased from Guangdong Medical Laboratory Animal Center, China, the production license number is SCXK (Guangdong) 2017-0125. $\mathrm{Apc}^{\mathrm{Min} /+} ; \mathrm{MMP}^{-/-}$hybrid mice were obtained by hybridizing $\mathrm{Apc}^{\mathrm{Min} /+}$ mice with $\mathrm{MMP}^{-/-}$ mice (Fig. S1A). All mice were housed under specificpathogen-free conditions. All animal studies were complied with Guangdong Pharmaceutical University, and all protocols were approved by the Animal Experimental Ethics Committee of Guangdong Pharmaceutical University.

\section{Genotype identification}

Male $\mathrm{Apc}^{\mathrm{Min} /+}$ mice were hybridized with female C57 mice and bred to create $\mathrm{Apc}^{\mathrm{Min} /+}$; MMP12 $2^{-/-}$hybrid mice. Genotype identification were performed on the 3-week-old mice The PCR products were subjected to gel electrophoresis (1.2\%), and a gel imaging system 
(GboxGyngene system, UK) was used to obtain electrophoresis images (Fig. S1B). Details of genotype identification can be found on the website of The Jackson Laboratory or Gem Pharmatech, China (850 point mutation).

\section{Mouse experiments and clinical human tissue collection}

Bone marrow, blood, inguinal white adipose tissue (iWAT), interscapular brown adipose tissue (BAT), gastrocnemius and soleus muscles were collected after euthanizing mice with carbon dioxide.

For immunohistochemistry staining analysis, muscle tissues were obtained from the residual tissue of patient who underwent clinical trauma surgery. All clinical fresh blood samples were collected from the Cancer Center of Sun Yat-sen University in Guangzhou, China, including healthy individuals who served as controls and patients with CRC (30-60years old, excluding patients with diabetes and hyperthyroidism) in the experimental group.

\section{Antibodies}

Anti-F4/80 (Cat.:14-4801-81) and anti-MMP12 (Cat.: MA5-24851) were purchased from eBioscience and Thermo Fisher, respectively. Anti-GAPDH (Cat.: 5174P) and anti- $\beta$-actin (Cat.: 4970S) were purchased from Cell Signaling Technology Inc. (CST). Recombinant mouse MMP-12 protein (Cat.: 3467-MPB-020) was purchased from R\&D Systems, Inc. Alexa Fluor-488 donkey antibody (Cat.: P/N SA11055S) was purchased from Thermo Fisher Scientific, Cambridge, Massachusetts, USA.

\section{Cell culture}

RAW264.7, MC38 and CT26 cell lines were purchased from American Typical Culture Collection (ATCC) and cultured according to international standard protocols. All cell lines were maintained in Dulbecco's Modified Eagle's Medium (DMEM, Thermo Scientific HyClone, Beijing, China) $+10 \%$ fetal bovine serum (HyClone) $+1 \%$ penicillin/streptomycin (HyClone) and cultured in DMEM. All cell lines in the experiments were incubated at $37^{\circ} \mathrm{C}, 5 \% \mathrm{CO}_{2}$.

\section{Total RNA extraction and real-time PCR}

All tissues from mice were stored at $-80^{\circ} \mathrm{C}$ until dissolved in Trizol. RNA extraction was performed according to the manufacturer's instructions, and the total extracted RNA was reverse-transcribed into cDNA for PCR amplification using the real-time polymerase chain reaction SYBR Green kit (TaKaRa, China). Steps of PCR were as follows: denaturation at $94^{\circ} \mathrm{C}$ for $5 \mathrm{~min} ; 40$ cycles of denaturation at $94^{\circ} \mathrm{C}$ for $30 \mathrm{~s}$, annealing at $60^{\circ} \mathrm{C}$ for $30 \mathrm{~s}$, and extension at $72^{\circ} \mathrm{C}$ for $30 \mathrm{~s}$; extension at $72^{\circ} \mathrm{C}$ for $5 \mathrm{~min}$. The mRNA samples were quantified in triplicate.
The housekeeping gene GAPDH was used as an internal control to normalize the real-time PCR data for each mRNA sample. All real-time PCR primers were synthesized by Shanghai Sangon Biotechnology Inc., China, and the primer sequences are listed in S Table 1.

\section{Histological analysis and Hematoxylin and eosin staining}

All tissues were fixed with $10 \%$ neutral buffer formalin and embedding in paraffin after dehydration. The $3-\mu \mathrm{m}$ tissue sections were treated with hematoxylin eosin, immunohistochemical staining and immunofluorescence staining, respectively. In this study, muscle fiber area was assessed using imageJ software after hematoxylin and eosin staining. ImageJ software was used to analyze color statistics of the cross-sectional area. Muscle area was selected after setting the threshold.

\section{Immunohistochemistry}

Tissue sections were dewaxed and incubated with 3\% hydrogen peroxide in methanol and blocked with $10 \%$ bovine serum albumin diluted with phosphate buffered saline (PBS). The sections were then incubated with primary antibodies at $4{ }^{\circ} \mathrm{C}$ overnight. After treated with horseradish-peroxidase-conjugated secondary antibody (1:100), the sections were color development with $\mathrm{DAB}$ and then stained with hematoxylin for microscopic observation. PBS as the negative control.

\section{Dual immunofluorescence staining}

Tissue sections were dewaxed and blocked with $10 \%$ bovine serum albumin in PBS solution. The sections were incubated with a mixture of primary antibodies (antiMMP12 antibody, 1:100, and anti-F4/80 antibody, 1:100) overnight at $4^{\circ} \mathrm{C}$. The primary antibody-treated sections were then incubated with a mixture of secondary antibodies (conjugated Alexa Fluor 488, 1:100, and Alexa Fluor $555,1: 100)$ for $1 \mathrm{~h}$ at room temperature. Immunostaining signals and DAPI-stained nuclei were visualized under a confocal microscope.

\section{ELISA assay}

ELISA was performed to test serum samples from patients and mice following the manufacturer's protocol. The human-IL-6 kit (Cat.EHC007), mouse JE/MCP1/ CCL2 kit (Cat.EMC113), mouse IL-6 ELISA kit (Cat. EMC004), and mouse KC/IL-8/CXCL1 ELISA kit (Cat. EMC104) were purchased from NeoBioscience Technology Company (ShenZhen, China). The rat/mouse insulin kit (Cat.EZRMI-13K) was purchased from EMD Millipore Corporation. Mouse MMP12 ELISA kit (Cat. ARG81803, Arigo Biolaboratories) and human CXCL1/ KC kit (Cat. EK-196, Multi Science Company). ELISA data were analyzed by Curve Expert 1.4 software. 


\section{Western blot}

Tissue samples (50-80 $\mu$ g) and cells were homogenized and lysed with radioimmunoprecipitation assay buffer (Thermo Scientific, Cat.: 89900) containing protease and phosphatase inhibitors, and then centrifuged to collect supernatants. Quantitative analysis based on the bicinchoninic acid (BCA) protein assay was used to determine protein concentration. Denatured proteins were separated by sodium dodecyl sulfate-polyacrylamide gel electrophoresis (10\% SDS-PAGE) and transferred to polyvinylidene difluoride (Millipore Corporation, Billerica, MA, USA) membranes, blocked with $5 \%$ nonfat milk, and then incubated with primary antibodies overnight at $4{ }^{\circ} \mathrm{C}$. Next day, the protein strips were further incubated with horseradish-conjugated secondary antibodies (1:5000) and the bands were developed with enhanced chemiluminescence detection solutions. ImageJ software was used to analyze optical density of the bands. All experiments were repeated three times.

\section{Oral glucose tolerance test (OGTT), insulin tolerance test (ITT) and blood glucose level measurement}

OGTT: After fasting for $8 \mathrm{~h}$, the mice were given $2 \mathrm{~g}$ of glucose per kilogram of body weight orally. Fasting blood and then blood samples were collected at 30,60, 90, and $120 \mathrm{~min}$, respectively. ITT: After fasting for $8 \mathrm{~h}$, the mice were intraperitoneally injected with $0.75 \mathrm{IU}$ of insulin per kilogram of body weight. Fasting blood and then blood samples were collected at $30,60,90$, and $120 \mathrm{~min}$, respectively. The whole blood glucose level is measured at the tail vein using a blood glucose meter.

\section{Serum lipid assay}

Levels of total cholesterol (TC), total triglycerides (TG), high density lipoprotein cholesterol (HDL-C) and low density lipoprotein cholesterol (LDL-C) were determined according to the manufacturer's protocols. All assay kits were purchased from Jiancheng Biotech (Nanjing, China).

\section{Cytokine Array}

The culture media with MC38 or non-MC38 cells was detected with Ray Bio Mouse Cytokine Antibody Array 5 (Cat.: AAM-INF-1-2, 38 cytokines, Ray Biotech) according to manufacturer's protocol. In brief, the membranes were blocked by incubated with the blocking buffer. Diluted biotin-conjugated anti-cytokine antibodies and HRP-conjugated streptavidin were used to develop positive signal. The visualized X-ray film was exposed to enhanced chemiluminescence (ECL) for quantification. Data analysis was performed using ImageJ to determine signal intensity, and positive controls were used to normalize the data. Each ratio of cytokine density to positive control density represents the relative content of every cytokine. The cytokines and their abbreviations are shown in Fig. S7.

\section{Co-culture experiment}

All cells were grown in a mixture of DMEM $+10 \%$ FBS $+10 \%$ penicillin-streptomycin. The co-culture of RAW264.7 and MC38/CT26 cells were seeded in 6-well dishes (Corning, NY, USA) using a chamber with filter inserts (pore size: $0.4 \mu \mathrm{m}$ ). None of the cell lines could pass through the filter because the pore size of the filter was smaller than the diameter of the cell lines. RAW264.7 cells without co-cultured MC38/CT26 cell lines (MC38/CT26) were used as negative controls. MC38/ CT26 cell lines (positive controls, $1 \times 10^{4}, 3 \times 10^{4}, 5 \times 10^{4}$ ) were seeded in the upper chamber, while RAW264.7 cells (negative controls, $1-2 \times 10^{5}$ ) were seeded in the lower chamber. We then physically separated RAW264.7 cells from MC38/CT26 cell lines to obtain RAW264.7 cells in the lower chamber. The RAW264.7 cells were homogenized and lysed with immunoprecipitation buffer for quantitative analysis and then subjected to western blot.

\section{Macrophages treated with IL- 6}

IL-6 (Cat. No.: 216-16, PeproTech) was dissolved in aqueous solutions of trehalose plus bovine serum albumin (BSA). RAW264.7 cells $\left(1-2 \times 10^{5}\right)$ were seeded in 6-well plates and treated with increased doses of IL-6 (0, 2, 5 $10,30 \mathrm{ng} / \mathrm{ml}$ ) for $72 \mathrm{~h}$. Cells incubated with fresh media without IL-6 were used as the negative controls (-IL-6). Finally, western blot was used to quantify MMP12 in RAW264.7 cells under different conditions.

\section{Isolation of primary peritoneal macrophages}

24-week-old WT and $\mathrm{Apc}^{\mathrm{Min} /+}$ mice were sterilized with $75 \%$ ethanol after cervical dislocation. The mouse abdomen was opened from the peritoneum, and $5 \mathrm{~mL}$ fetal bovine serum was injected using a syringe. After $5 \mathrm{~min}$, the peritoneal fluid was collected and transferred to a $15 \mathrm{~mL}$ tube to obtain peritoneal macrophages. After centrifuging $(1000 \mathrm{rpm})$ for $10 \mathrm{~min}$ and removing the supernatant, the pelleted cells were resuspended in DMEM and then cultured at $37^{\circ} \mathrm{C}$ for $2 \mathrm{~h}$.

\section{MMP12 and peptide interaction experiments}

Recombinant mouse MMP-12 protein (Cat. No.:3467MPB-020) was purchased from R\&D Systems, Inc. Following the manufacturer's instructions, MMP12 was dissolve at a concentration of $250 \mu \mathrm{g} / \mathrm{ml}$ in a pH7.5 buffer containing $50 \mathrm{mM}$ Tris, $10 \mathrm{mM} \mathrm{CaCl}, 150 \mathrm{mM} \mathrm{NaCl}$, $0.05 \%(\mathrm{w} / \mathrm{v}) \mathrm{Brij}-35$, and $5 \mu \mathrm{M} \mathrm{ZnCl}_{2}$. Insulin polypeptide and insulin-like factor polypeptide were synthesized by ChinaPeptides (Shanghaih, China). 
The sequence of insulin and IGF-1 are 5-FAMNQHLCGSHLVEALYLVCGERGFFYTPK (Dabcyl) and 5-FAM-GPETLCGAELVDALQFVCGDRGFYFNK (Dabcyl), respectively. The peptide freeze-dried powder was dissolved in $25 \% \mathrm{ACN}$ and $75 \% \mathrm{dd}_{2} \mathrm{O}$ solvent at a concentration of $1 \mathrm{mg} / \mathrm{ml}$. For fluorescence intensity test, after mixed incubation of MMP12 and peptide $\left(37^{\circ} \mathrm{C}, 2 \mathrm{~h}\right)$, the fluorescence intensity was measured using a fluorescence microplate reader. For IMS Analysis, after MMP12 and peptide were mixed and incubated, the lower liquid filtered by a $34 \mathrm{KD}$ filter was subjected to Electrospray Ionization Mass Spectrometry (ESI-MS) to detect its characteristic peaks, and the experimental conditions were: Ion Source: ESI, Capillary (KV): \pm 2500 3000, Desolvation (L/hr): 800, Desolvation Temp: $450^{\circ} \mathrm{C}$, Cone $(\mathrm{V}): 30 \sim 50$, Run Time: $1 \mathrm{~min}$.

\section{Mice administration}

MMP408 (MMP12 inhibitor, Cat.: 444291, Merck), CAS 1258003-93-8, could control the biological activity of MMP-12 [33, 34]. All 17-week-old Apc ${ }^{\mathrm{Min} /+}$ mice were randomly divided into three groups $(n=5$ per group). One group of $\mathrm{Apc}^{\mathrm{Min} /+}$ mice were intragastrically administered with MMP408 at a dose of $5 \mathrm{mg} / \mathrm{kg}$, and the other group was intraperitoneally administered with 5-FU $(30 \mathrm{mg} / \mathrm{kg})$ combined with a dose of MMP408 by intragastric administration. Meanwhile, $\mathrm{Apc}^{\mathrm{Min} /+}$ mice injected with normal saline as the control. Body weight was measured after the administration every 2 days, which continued for 10 days. Weight changes were recorded.

\section{Data processing}

All mouse organ ratios were presented by the percentage of the organs/tissue weight to the body weight. The ratio of the skeletal muscle weight to the body weight was equal to (Gastrocnemius +Soleus muscle)/body (\%). All data were processed by using GraphPad Prism 8.0 software and were presented as the means \pm standard deviations (SD). A two-tailed test or a one-way ANOVA test was used to analyze the data. Statistically significant differences were considered at ${ }^{*} P<0.05$, ${ }^{* *} P<0.01$, ***P $P<0.001, * * * P<0.0001$. The schematic images were created on BioRender.com.

\section{Results}

MMP12 knockout leads to weight gain in Apc ${ }^{\mathrm{Min} /+}$ mice To investigate body weight change in wild type mice (WT mice) or Apc ${ }^{\mathrm{Min} /+}$ mice after MMP12 knockout, we determined their body weight from 5 to 24 weeks old. The weight curves showed that compared with weight gain in the WT mice 5 to 24 weeks, the body weight of $\mathrm{Apc}^{\mathrm{Min} /+}$ mice reached its maximum peak at 15 weeks old and then declined until the mice were sacrificed at approximately 24 weeks old $(P<0.5)$. Surprisingly, in comparison with the $\mathrm{Apc}^{\mathrm{Min} /+}$ mice group, the body weight of $\mathrm{Apc}^{\mathrm{Min} /+}$; $\mathrm{MMP}^{-/ 2} 2^{-/}$hybrid mice was increased by approximately $70 \%$ at the same age $(P<0.01)$. Meanwhile, there were no significant difference in the body weight between WT mice and MMP12 $2^{-1-}$ mice $(P>0.5$, Fig. $1 \mathrm{~A})$. $\mathrm{Apc}^{\mathrm{Min} /+}$ mouse model present cancer cachexia (CAC) like human being with tumor, with intestinal tumor burden and weight decrease dramatically. Since weight loss induced by CAC may be related to the wasting of skeletal muscle weight and fat weight [30], we hereby investigated whether weight gain in $\mathrm{Apc}^{\mathrm{Min} /+}$ mice caused by MMP12 knockout was due to a reduction in fat and skeletal muscle loss at 24 weeks old. The histological WAT of $\mathrm{Apc}^{\mathrm{Min} /+}$ mice and compared with that of WT mice. The WAT-to-body weight ratio of $\mathrm{Apc}^{\mathrm{Min} /+}$ mice was decreased; the ratio of $\mathrm{Apc}^{\mathrm{Min} /+}$; $\mathrm{MMP}^{2} 2^{-/-}$mice tended to increase compared with that of $\mathrm{Apc}^{\mathrm{Min} /+}$ mice, but the increase was not statistically significant (Fig. 1B). However, a significant increase of approximately $4.5 \%$ in the muscle-to-body weight ratio was observed in $\mathrm{Apc}^{\mathrm{Min} /+} ; \mathrm{MMP}^{-/-}$mice compared with Apc ${ }^{\mathrm{Min} /+}$ mice (Fig. 1C). To further confirm the histological changes in WAT (Fig. 1D) and muscle area (Fig. 1F) of the four mice group at 24 weeks old, the hematoxylin and eosin staining (H\&E staining) was used to assess the histological area by ImageJ software. We observed that the fat area was larger in $\mathrm{MMP} 12^{-/-}$mice compared with that in WT mice, but it the fat area was reduced between $\mathrm{Apc}^{\mathrm{Min} /+}$ mice and $\mathrm{Apc}^{\mathrm{Min} /+}$; $\mathrm{MMP}^{-1-}$ mice (Fig. 1E). While H\&E staining of muscle suggested that the area in $\mathrm{Apc}^{\mathrm{Min} /+}$; MMP12 ${ }^{-1-}$ mice was estimated to be approximately 1.2fold larger than that in $\mathrm{Apc}^{\mathrm{Min} /+}$ mice (Fig. 1G). Meanwhile, no difference in food intake was observed between $\mathrm{Apc}^{\mathrm{Min} /+}$ and $\mathrm{Apc}^{\mathrm{Min} /+} ; \mathrm{MMP}_{2}{ }^{-/-}$mice (Fig. S3A). Taken together, we think that knocking out MMP12 leads to weight gain and prevents muscle wasting in $\mathrm{Apc}^{\mathrm{Min} /+}$ mice.

\section{MMP12 is up-regulated in muscle tissue and peritoneal macrophages of $\mathrm{Apc}^{\mathrm{Min} /+}$ mice}

Based on the results above, we used immunohistochemical staining, immunofluorescence staining and western immunoblotting to detect and confirm whether MMP12 was expressed in muscle tissue. The immunohistochemistry results showed that MMP12 positive staining was expressed not only in skeletal muscles in human being (Fig. 2A and Fig. S3B), but also in mice (Fig. 2B). To further explore why muscle loss caused in $\mathrm{Apc}^{\mathrm{Min} /+}$ mice but not in WT mice by knocking out MMP12, we used immunohistochemistry to detect MMP12 in the muscle of 24-week-old WT mice and $\mathrm{Apc}^{\mathrm{Min} /+}$ mice, respectively 


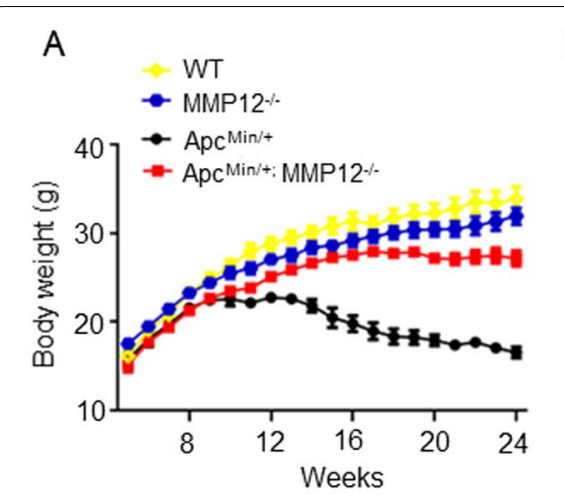

D

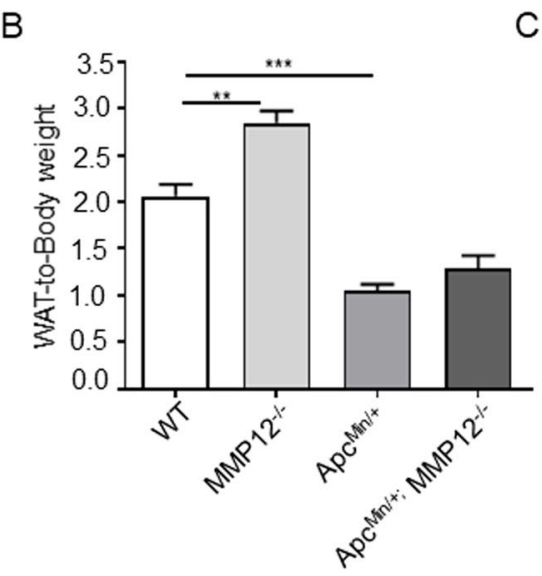

WT

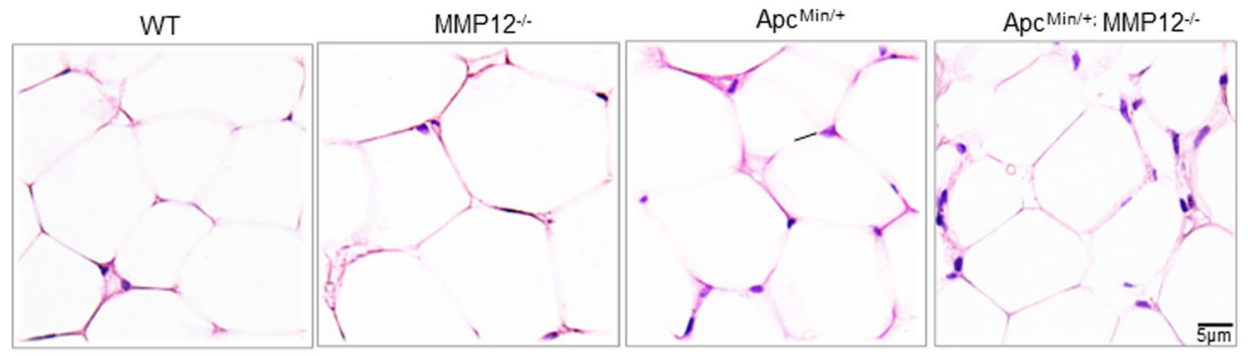

F
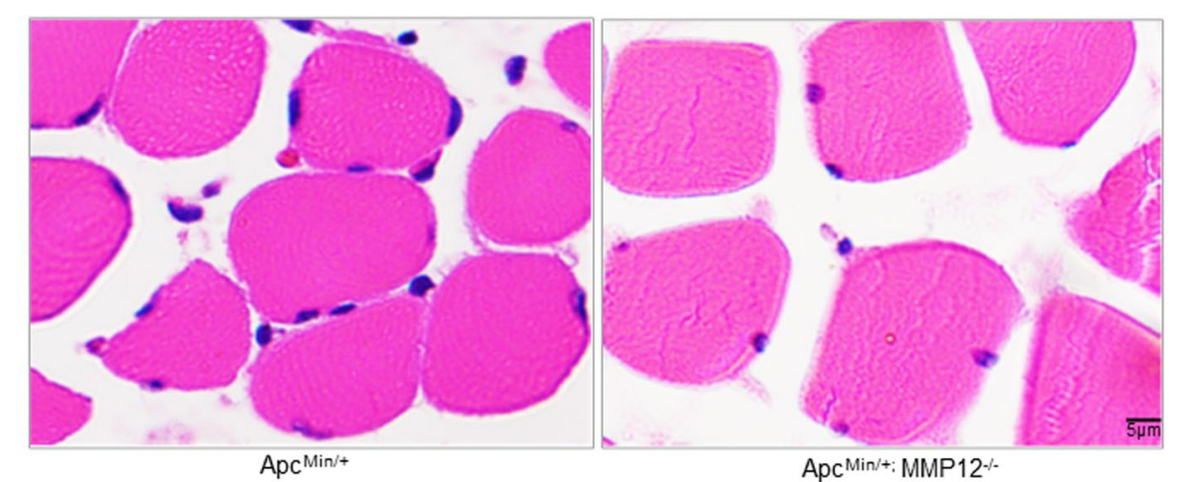

G

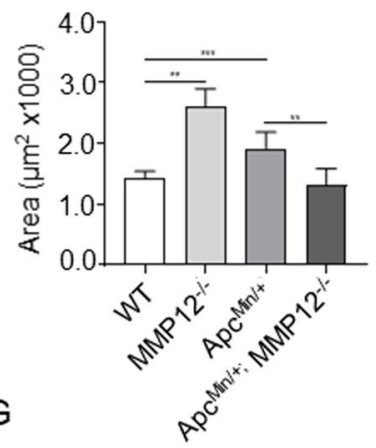

Fig. 1 Knockout of MMP12 in Apc Min/+ Mice Prevents Weight and Muscle Loss. A Plots of the body weight of wild-type (WT), Apc ${ }^{\mathrm{Min} /+}, \mathrm{Apc}^{\mathrm{Min} /+}$; MMP12 $2^{-/-}$and MMP12 $2^{-/-}$mice from 5 to 24 weeks ( $n=6$ per group). B The ratio of inguinal white adipose tissue to body weight (***P $P 0.001$; $\left.{ }^{*} P<0.01, n=5\right)$. C The ratio of skeletal muscle to body weight $\left.{ }^{*} P<0.05, n=5\right)$. $\mathbf{D}$ Hematoxylin and eosin staining of inguinal white adipose tissue

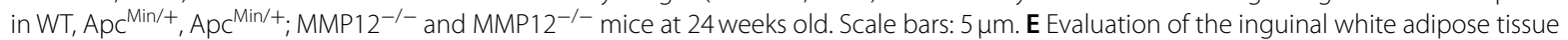
across 4 groups by ImageJ software $(40 X)\left({ }^{* *} P<0.001 ;{ }^{* *} P<0.01\right.$, Each cell area are shown as means $\pm S D ; n=5$ mice per group). $\mathbf{F}$ Hematoxylin and eosin staining of muscle in $\mathrm{Apc}^{\mathrm{Min} /+}$ and $\mathrm{Apc}^{\mathrm{Min} /+} ; \mathrm{MMP}^{-12^{-/}}$at 24 weeks old. Scale bars: $5 \mu \mathrm{m}$. G Evaluation of the cross-sectional area of the gastrocnemius from $\mathrm{Apc}^{\mathrm{Min} /+}$ mice and $\mathrm{ApC}^{\mathrm{Min} /{ }^{+}} ; \mathrm{MMP}^{2} 2^{-/-}$mice by ImageJ software (40X) ${ }^{*} P<0.05$; data are shown as means $\pm \mathrm{SD} ; n=6$ mice per group)

(Fig. 2B). Immunohistochemical staining results showed that MMP12-positive staining was increased in the muscle tissue of $\mathrm{Apc}^{\mathrm{Min} /+}$ mice compared with that of WT mice at 24 weeks old (Fig. 2C). MMP12 is mainly secreted by macrophages [15], we next performed dual immunofluorescence (IF) to determine whether MMP12 and macrophages were co-expressed in muscle tissues, and results indicated that F4/80 (macrophage cell marker) and MMP12 protein co-localized in muscle tissues (Fig. 2D). Next, Quantitative PCR (qPCR) revealed 


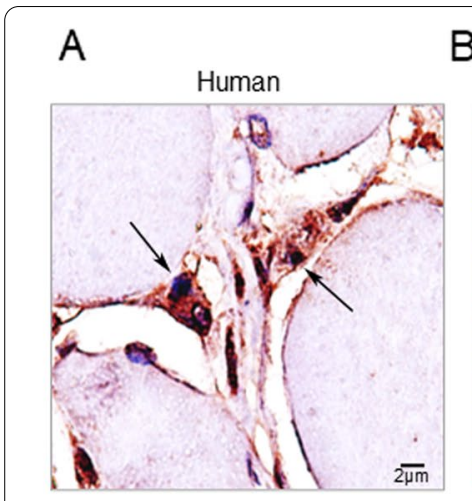

B
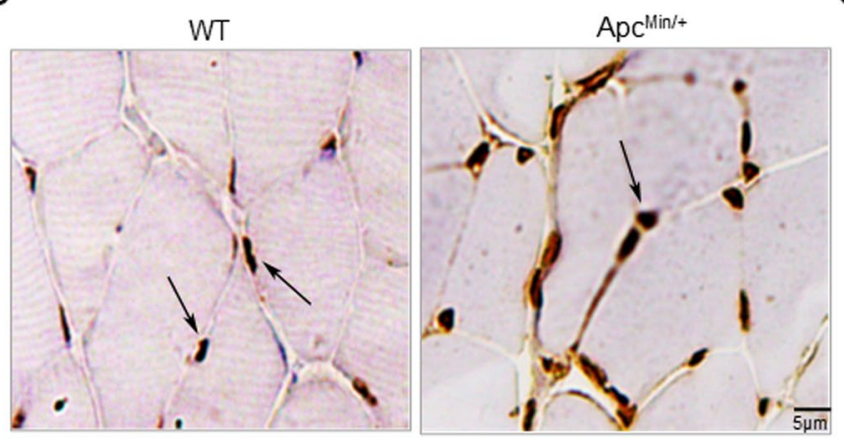

C

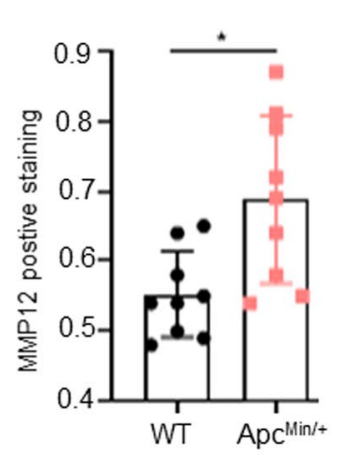

D
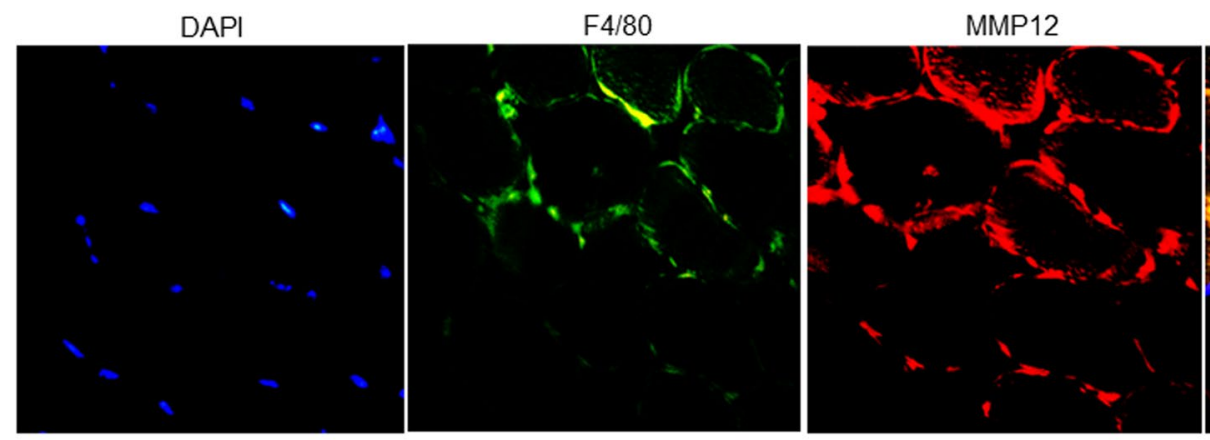

F4/80/MMP12/DAPI

E

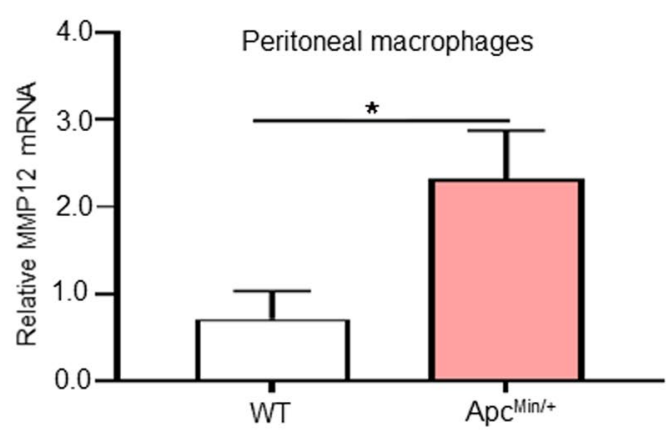

F

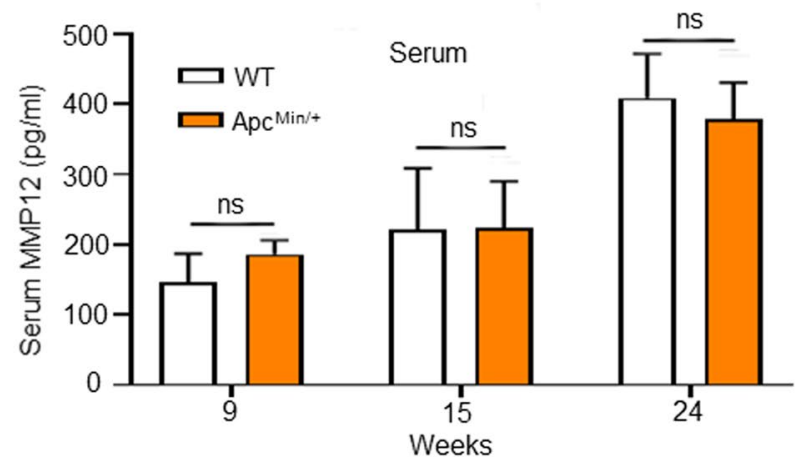

Fig. 2 MMP12 Is Up-regulated in Muscle Tissues and Macrophages of Apc Min/+ Mice. A MMP12 antibody immunostaining in the muscle of healthy individuals. Scale bar: $2 \mu \mathrm{m}$. B Immunostaining of MMP12 in muscle tissue of WT mice and Apc ${ }^{\mathrm{Min} /+}$ mice. Scale bar: $5 \mu \mathrm{m}$. C Quantification of MM12 expression in gastrocnemius tissue was performed by ImageJ software (40X) ( ${ }^{*} P<0.05$, data are shown as means $\pm S D ; n=9$ per group). $\mathbf{D}$ Representative images of dual immnofluorescent staining of macrophages (F4/80 in green) and MMP12 (in red) in WT mice are shown. The yellow areas in the merged images indicate overlapping localization of the red and green signals, indicated by the white arrows. Scale bars: $20 \mu \mathrm{m}$. $\mathbf{E}$ Quantification of MMP12 mRNA level in peritoneal macrophages isolated from WT mice and Apc ${ }^{\text {Min/+ }}$ mice by qPCR $\left({ }^{*} P<0.05\right.$; data are shown as the means $\pm \mathrm{SD} ; n=6$ per group). F The serum MMP12 levels detected in WT and Apc ${ }^{\mathrm{Min} /+}$ mice at 9, 15, and 24 weeks old by ELISA ( $P>0.05 ;$ data are shown as means $\pm \mathrm{SD} ; n=6$ per group)

that a tendency towards higher MMP12 mRNA levels in peritoneal macrophages (as described in the Materials) was observed in the $\mathrm{Apc}^{\mathrm{Min} /+}$ mice (Fig. 2E), which was consistent with the immunohistochemistry results. Then MMP12 levels in serum were detected with ELISA kit, the data showed that they were not significantly different between the 9-, 15-, and 24-week-old WT mice and the $\mathrm{Apc}^{\mathrm{Min} /+}$ mice (Fig. 2F). In summary, MMP12 was co-expressed with macrophage in muscle tissue. MMP12 was increased in skeletal muscle tissue and peritoneal 
macrophages of $\mathrm{Apc}^{\mathrm{Min} /+}$ mice but in serum. In addition we have also evaluated the mRNA expression of MMP12 in other tissues (Fig. S3C, obtained from The Cancer Genome Atlas).

\section{IL-6 are increased in tumor cells, serum and Colon Cancer tissue}

Previous studies have shown that IL-6 is one of the predictors of CAC-induced muscle atrophy [75-78], which may aggravate the disease development. IL-6 in tumor biopsy tissue is a biomarker for the diagnosis of cancer cachexia, and tumor cells are an important source of IL-6 $[20,26,35]$. Clinical literature also suggested that IL-6 is almost the only cytokine that increases among various factors in many patients with CAC muscle atrophy who lose weight. Therefore, we focused on investigating whether IL-6, which is associated with muscle atrophy and cancer cells. Cytokine microarray was used to determine which cytokines were up-regulated in the supernatant of MC38 mouse colon cancer cell line. Previous studies have reported that both MC38 and CT26 mouse colon cancer cells can up-regulate IL-6 expression [36]. In vitro protein microarray experiments showed that IL-6 expression was higher in the supernatant after cultured with MC-38 cells (Fig. 3A, B). Hence, we focus on studying IL-6. Clinical data also showed that serum IL-6 in colorectal cancer patients were significantly higher than the healthy group (Fig. 3C). A similar trend was also found in $\mathrm{Apc}^{\mathrm{Min} /+}$ mice serum that IL-6 levels in $\mathrm{Apc}^{\mathrm{Min} /+}$ mice were significantly increased compared with that in WT mice at 15 to 24 weeks old (Fig. 3D). We also detected by qPCR that the IL- 6 mRNA levels was higher in the stripped intestinal tumor tissues of $\mathrm{Apc}^{\mathrm{Min} /+}$ mice than in the normal intestinal epithelium of WT mice (Fig. 3E). Taken together, serum IL-6 was up-regulated in

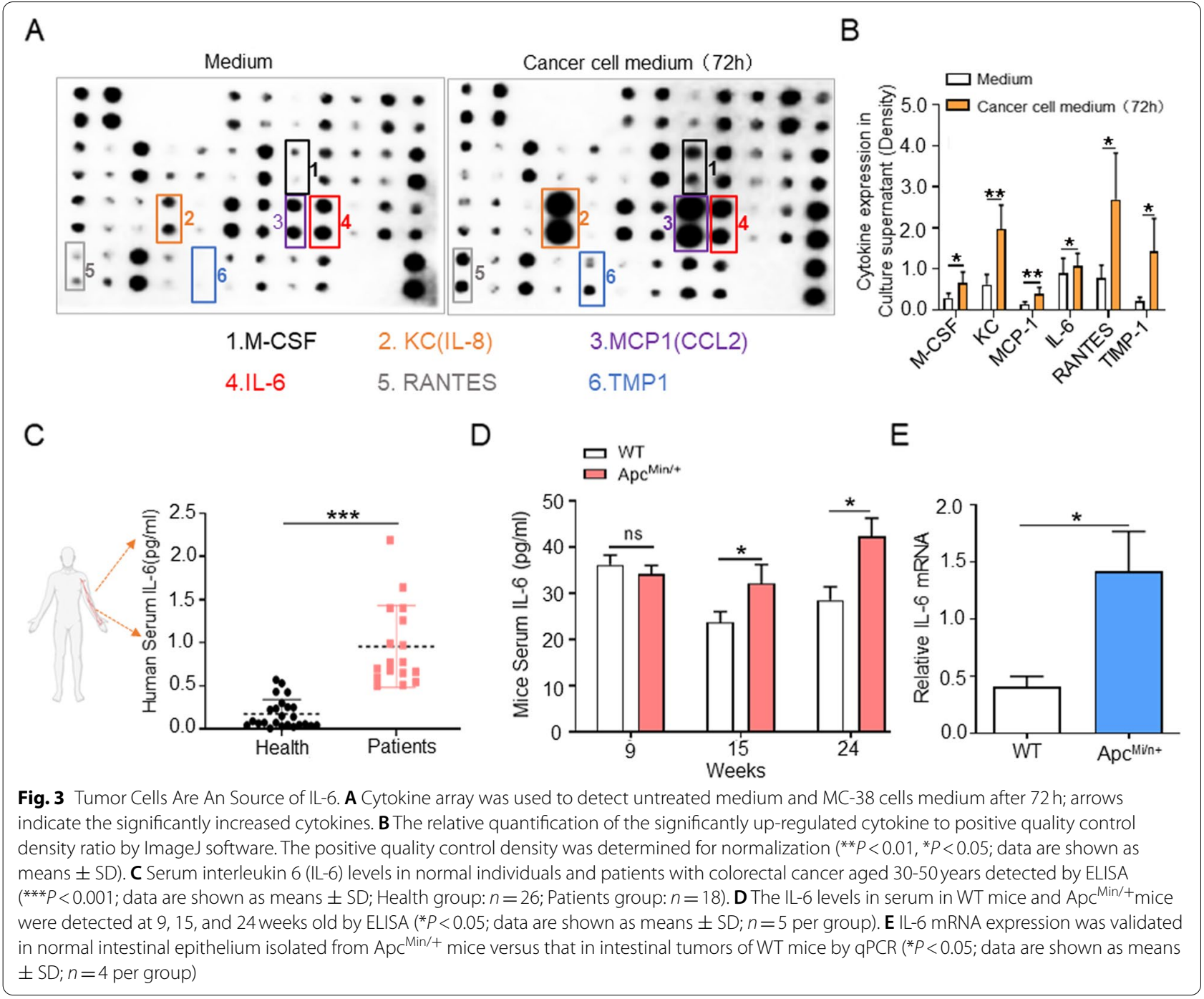


colorectal cancer patients and in $\mathrm{Apc}^{\mathrm{Min} /+}$ mice, and IL-6 was increased in both colorectal cancer tissues and cells.

\section{IL-6 up-regulate MMP12 of macrophages}

Previous studies reported that IL-6 might not directly lead to muscle loss in CAC $[26,37]$. IL-6 in the tumor microenvironment are an important determinant of alternative macrophage activation and could induce macrophage M2 polarization, and M2 macrophages can produce MMP12 [38, 39]. Taken together, we speculated that tumor cells release IL-6 to stimulate macrophages to upregulate MMP12. In order to reveal the potential association between tumor-derived IL- 6 and macrophages, we performed that mouse macrophage RAW264.7 cells were co-cultured with mouse colorectal cancer MC38 cells / CT26 cells, after $72 \mathrm{~h}$ to detect MMP12 in macrophages by western blot (Fig. 4A). Results showed that RAW264.7 cells exhibited increased MMP12 expression as the number of MC38 cells increased, compared with RAW264.7 cells cultured alone as the negative control group (Fig. 4B, C). Similar trends were observed in CT26 cells (Fig. 4D, E). We further treated RAW264.7 cells with IL-6 using different concentrations. RAW264.7 cells were seeded in 6-well plates and treated with increasing doses of IL-6 $(0,2,5,10,30 \mathrm{ng} / \mathrm{mL})$ for $72 \mathrm{~h}$. Cells incubated with fresh media were used as the untreated negative controls (Fig. 4F). For RAW264.7 cells treated with IL-6, we assessed MMP12 levels by western blot. We found that within a certain concentration range $(<30 \mathrm{ng} /$ $\mathrm{ml})$, as the IL- 6 dose was increased, MMP12 expression in RAW264.7 cells was also elevated when treated with IL-6 (Fig. 4G, H). Meanwhile, immune gene data suggested that IL-6 receptor (IL-6R) was highly expressed on myeloid cells including $\mathrm{F} 40^{+}$macrophages (Fig. 4I). Altogether, these findings indicate that IL-6 can stimulate macrophages and up-regulate MMP12 in macrophages.

\section{MMP12 degrade insulin and insulin-like growth Factor-1}

Above results suggest that IL-6 can up-regulate MMP12 in macrophages. MMP12 knockout can reduce muscle loss in $\mathrm{Apc}^{\mathrm{Min} /+}$ mice. It is important that insulin and insulin-like growth factor 1 (IGF-1) have complex anabolic effects and are important regulators of muscle remodeling that can mediate muscle atrophy [40-44]. Moreover, Jung-Ting Lee proposed that MMP12 expression significantly promotes insulin resistance and that insulin were regulated by resident macrophages [15]. Hereby we hypothesized that MMP12 may degrade insulin or IGF-1 which could impact muscle loss as previously reported [17].

Firstly, we labeled insulin polypeptide with FAM and DABCLY on the $\mathrm{N}$ side and the $\mathrm{C}$ side. The insulin peptide was labeled with FAM $(488 \mathrm{~nm})$ and DABCLY (quenching fluorescence). When the insulin peptide was broken, FAM was then observed at $488 \mathrm{~nm}$ (resonance energy transfer, FRET). Then we found that the insulin peptide incubated it with seum, with the absorbance peak appearing at $\lambda=488 \mathrm{~nm}$ (Fig. 5A). Because IGF-1 is similar to insulin in structure, we further evaluated the relationship between IGF-1and MMP12, and measured its fluorescence intensity and characteristic peak at $488 \mathrm{~nm}$ (Fig. 5 A,B). The dose of insulin and IGF-1 fluorescent peptide was constant with MMP12, the more MMP12 protein was present, the stronger the fluorescence intensity was, as shown in Fig. 5C. Results of electrospray ionization mass spectrometry (IMS) showed that after incubated with MMP12 protein, insulin was decomposed into different fragments (Fig. S2A), and its characteristic peak changed from $(\mathrm{m} / \mathrm{z}=436.99)$ to various $\mathrm{m} / \mathrm{z}$ characteristic peaks. Similarly, IGF-1 was cleaved into fragments with different $\mathrm{m} / \mathrm{z}$ after incubated with MMP12, and its characteristic peak $(\mathrm{m} / \mathrm{z}=436.98)$ was also altered (Fig. S2B). We hypothesized that insulin and IGF-1 might be broken down into different amino acid groups by MMP12. Totally, MMP12 may degrade insulin and IGF-1, and it seems that the degradation is stronger on IGF-1 than on insulin.

In addition, our other data supports that knocking out MMP12 in $\mathrm{Apc}^{\mathrm{Min} /+}$ mice may reduce insulin levels or increase insulin sensitivity, which could contribute to reversing insulin resistance (Fig. S6A-H), while it was not related to the basic function of islets based on results of H\&E staining and IHC staining (Fig. S4E-H).

\footnotetext{
(See figure on next page.)

Fig. 4 IL-6 Up-regulates MMP12 in Macrophages. A Schematic diagram of tumor cells (MC38/CT26 cell lines) co-cultured with macrophage cells (RAW264.7 cell lines). All quantifications were performed by image J software for gray scale statistics. B, C Representative western blots showing the secreted MMP12 protein levels from RAW264.7 cell lines $\left(1-2 \times 10^{5}\right)$ cultured alone or co-cultured with MC38 cell lines (control, $1 \times 10^{4}, 3 \times 10^{4}$, $\left.5 \times 10^{4}\right)$. $\beta$-Actin as the internal control. D, E Representative western blots showing the secreted MMP12 protein levels from RAW264.7 cell lines $\left(1-2 \times 10^{5}\right)$ cultured alone or co-cultured with CT26 cell lines (control, $\left.1 \times 10^{4}, 3 \times 10^{4}, 5 \times 10^{4}\right)$. GAPDH as the internal control. F Schematic diagram of IL-6 treated macrophages. RAW264.7 cells incubated with fresh media were served as untreated negative controls. Western blot was used to detect MMP12 in RAW 264.7 cells and GAPDH as the internal control. G, H RAW264.7 cells $\left(1-2 \times 10^{5}\right)$ were seeded in 6-well plates and treated with increasing doses of IL-6 (0, 2, 5, 10, $30 \mathrm{ng} / \mathrm{mL})$ for $72 \mathrm{~h}$. I Immune Gene data (https://www.immgen.org/ImmGenApps.html) suggest that IL-6 receptor expresses on F480+ macrophages. The colored bars refer to the expression level of IL-6 receptors on macrophages. Red represents high expression of IL-6 receptors, and green represents low expression of IL-6 receptors
} 


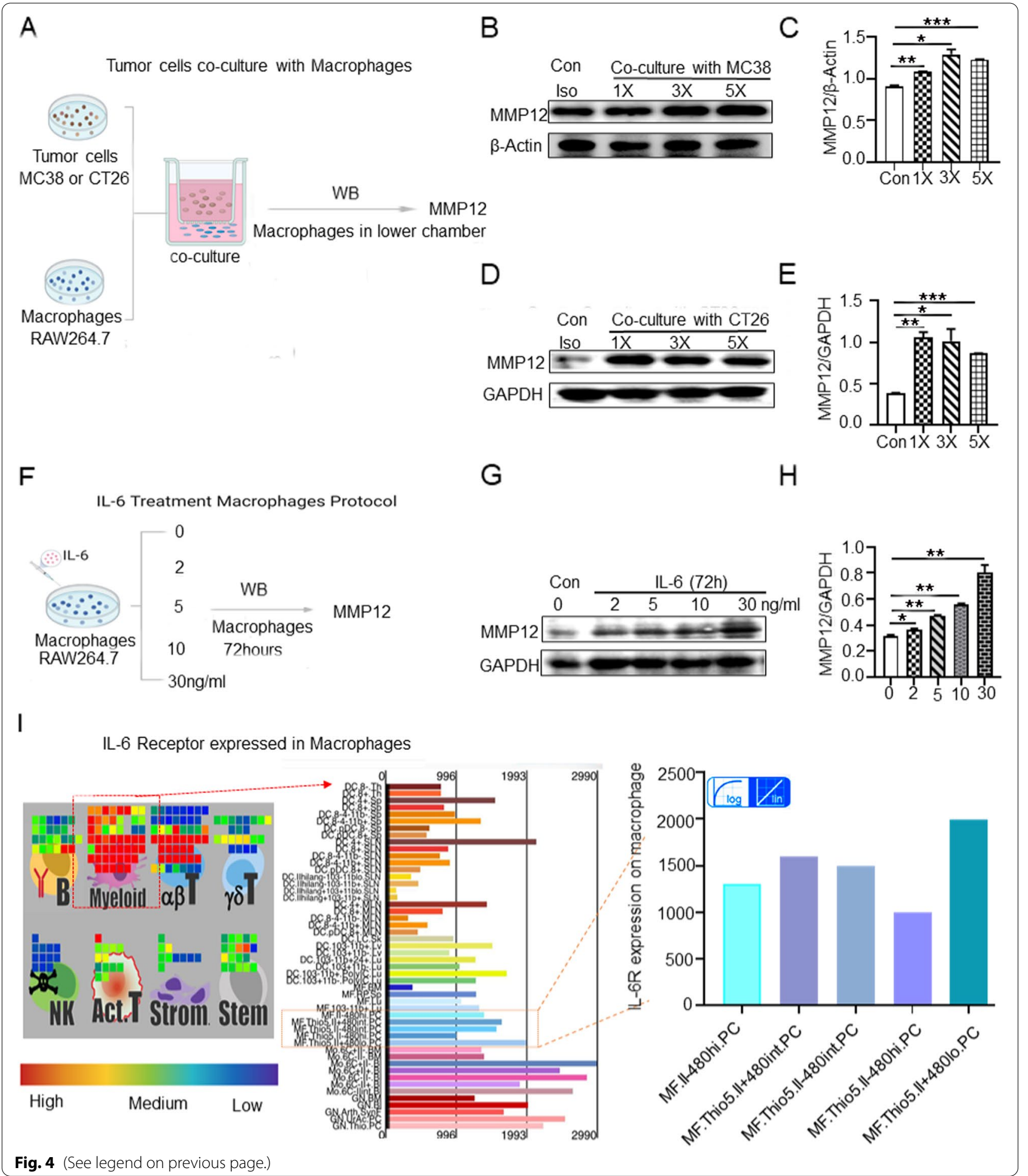

MMP12 inhibitor reverses weight loss in $\mathrm{Apc}^{\mathrm{Min} /+}$ mice The insulin and IGF-1 can impact muscle loss caused by CAC and exacerbate weight loss [40, 43-45]. Therefore, we wonder whether MMP12 inhibitor would influence weight changes in $\mathrm{Apc}^{\mathrm{Min} /+}$ mice. To investigate the effect of inhibiting MMP12 on colorectal cancer or body weight, we administered MMP12 inhibitor (MMP408) and its combination with a classic clinical anti-colon 


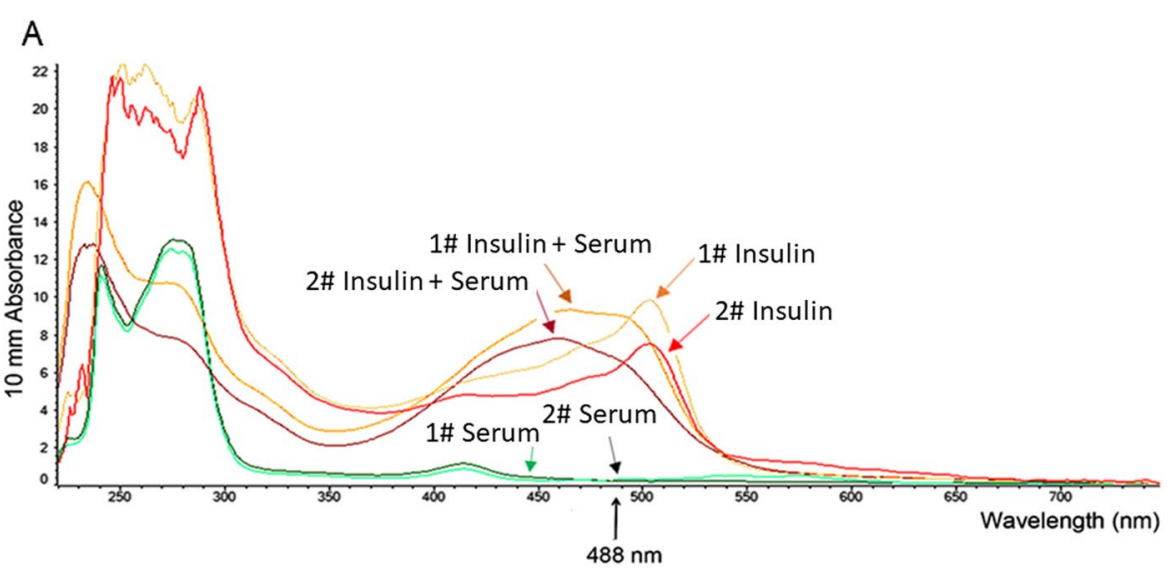

B

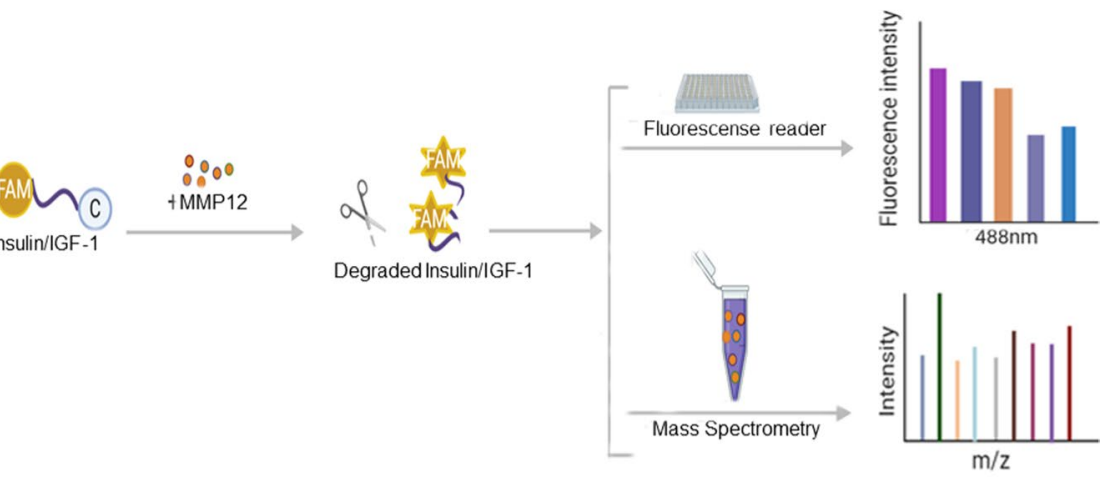

C
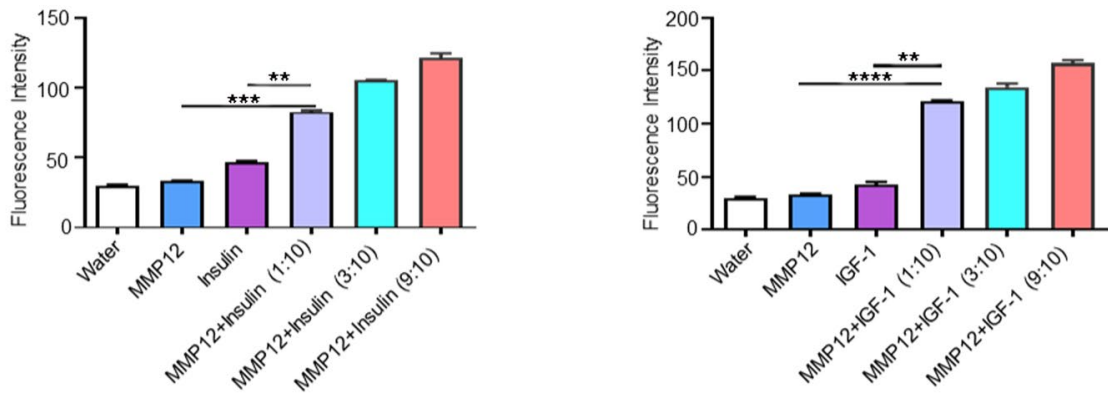

Fig. 5 MMP12 Degrades Insulin and Insulin-like Growth Factor-1. A Representative images of the peak were detected at $488 \mathrm{~nm}$ after the insulin peptide was degraded by normal mice serum. The insulin peptide was labeled with FAM (488 nm) and DABCLY (quenching fluorescence). When the insulin peptide was broken, FAM was then observed at $488 \mathrm{~nm}$ (resonance energy transfer, FRET). B The synthetic insulin (or IGF-1) peptide was labeled with FAM and DABCLY as shown. The insulin peptide was labeled with FAM $(488 \mathrm{~nm})$ and DABCLY (quenching fluorescence). When the insulin (IGF-1) peptide was broken, FAM was then observed at $488 \mathrm{~nm}$. Fluorescence intensity of the peak were detected at $488 \mathrm{~nm}$ after the insulin (IGF-1) peptide was degraded by MMP12 using a fluorescence microplate reader. Electrospray lonization Mass Spectrometry (IMS) was used to detect its characteristic peaks. C The MMP12 and insulin (or IGF-1) peptide interaction led to appearance of a fluorescence signal on dose-dependent $\left({ }^{* *} P<0.001,{ }^{* *} P<0.01\right.$; data are shown as means $\left.\pm \mathrm{SD}\right)$

cancer drug (5-FU) in $\mathrm{Apc}^{\mathrm{Min} /+}$ mice (Fig. 6A). After 2 weeks of administration, results showed that in 17-week-old Apc ${ }^{\mathrm{Min} /+}$ mice, weight loss in the MMP12 inhibitor group (MMP408 group) accounted for 5\% of the basal body weight, which was only one third of that of the control group (administered with normal saline), indicating a significant difference between the two groups. In the experiment group of combined MMP408 and anticancer drug (+MMP408/+5-FU), weight change was decreased by approximately $8 \%$ of the basal body weight, which was half that of the control group (+Control). Unfortunately, there were no changes in body weight in the anticancer drug combination group (+MMP408/+5-FU), when compared with those in the MMP12 inhibitor group alone (+MMP408) (Fig. 6B). 
A
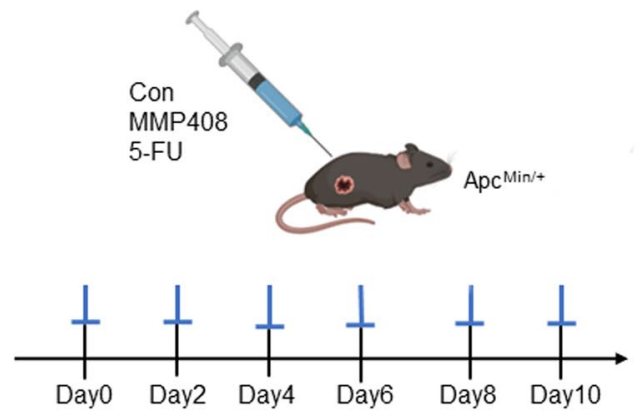

Changes of Body Weight

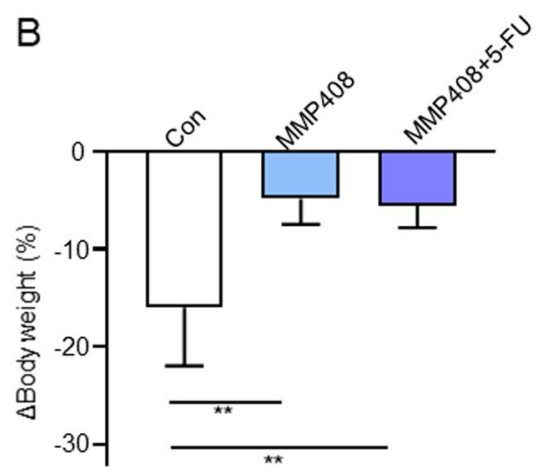

Fig. 6 Inhibiting MMP12 in Apc Min/+ Mice Slows Down Weight Loss. A Schematic diagram of the administration process of 17-week-old Apc ${ }^{\text {Min/+ }}$ mice. The drugs were given every 2 days (MMP408: $5 \mathrm{mg} / \mathrm{kg}, 5-\mathrm{FU}: 30 \mathrm{mg} / \mathrm{kg}$ ). The saline group was used as a control. B Percentage of weight gain compared to the basal weight after administration of drugs in $\mathrm{Apc}^{\mathrm{Min} /+}$ mice $\left({ }^{* *} P<0.01\right.$, data are shown as means $\pm \mathrm{SD} ; n=5$ per group)

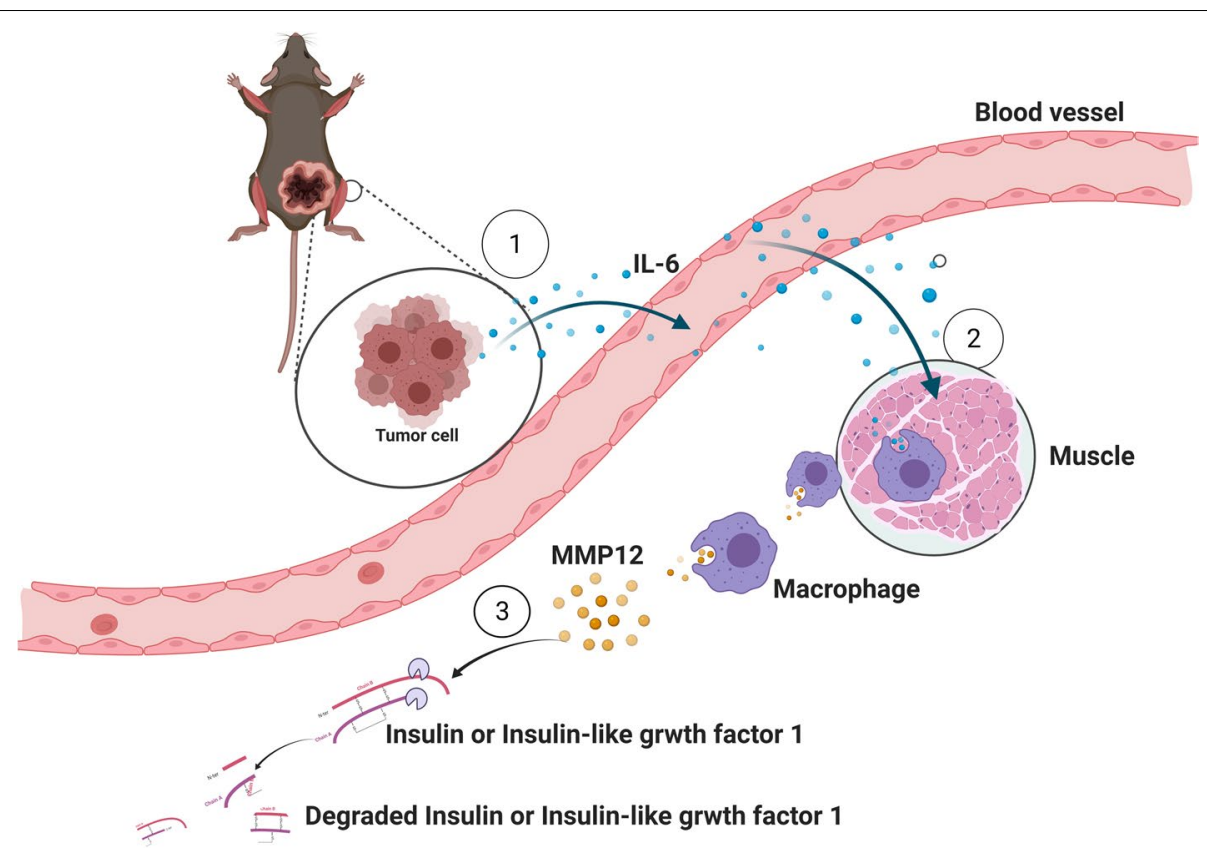

Fig. 7 The Schematic of the Crosstalk between Tumor Cells And Muscular Macrophages in Apc ${ }^{\text {Min/+ }}$ Mice via IL-6 And MMP12

In summary, the experiments above suggested that specifically inhibiting MMP12 in $\mathrm{Apc}^{\mathrm{Min} /+}$ mice can reduce weight loss.

Lastly, we think that it exist the crosstalk between cancer cells and macrophages in muscle tissues, it is that tumor cells secrete IL-6 inducing macrophages to up-regulate MMP12 which degrade insulin and IGF-1 in muscle tissue (Fig. 7).

\section{Discussion}

Weight loss has received more and more attention in various diseases, such as diabetes, abnormal thyroid metabolism, weight control, cancer, etc. More than four-fifths of patients with CAC died from extreme loss of body weight and skeletal muscle. Our study suggests that MMP12 plays a new role in controlling weight and muscle loss in $\mathrm{Apc}^{\mathrm{Min} /+}$ mice, and inhibiting MMP12 can reverse the body weight reduction associated with $\mathrm{CAC}$ in mice. 
The clinical definition of CAC by Fearon criteria includes the following characteristics: weight loss $>5 \%$ or weight loss $>2 \%$ and a $\mathrm{BMI}<20 \mathrm{~kg} / \mathrm{m}^{2}$ or sarcopenia [46]. In this study, 15- to 24-week-old $\mathrm{Apc}^{\mathrm{Min} /+}$ mice with weight loss $>15 \%$, as well as skeletal muscle (gastrocnemius and soleus) loss, and certain other symptoms such as anemia, were considered as the characteristics of CAC. The data of this study demonstrated that muscle weight and muscle cross-sectional area were increased in $\mathrm{Apc}^{\mathrm{Min} /+}$ mice. The data of $\mathrm{Apc}^{\mathrm{Min} /+}$; MMP12 $12^{-1-}$ mice, compared with those of $\mathrm{Apc}^{\mathrm{Min} /+}$ mice, indicated that knocking out MMP12 might suppressed body weight and skeletal muscle loss. Our previous study suggested that MMP12 knockout would increase tumor growth by impacting macrophage development, while there was no difference in the survival rate $[22,47]$, which can be explained by the protective effect of MMP12 knockout on the weight loss of tumor-bearing mice.

In our study, we weighed these mice tissue at 24 weeks old, and performed histological evaluation using H\&E staining. We found that knocking out MMP12 had some additional effect on weight of liver, BAT, and pancreas in $\mathrm{Apc}^{\mathrm{Min} /+}$ mice. Similarly, knocking out MMP12 in $\mathrm{Apc}^{\mathrm{Min} /+}$ mice did not cause changes in WAT, even though MMP12 knockout in WT mice resulted in increased and expanded WAT, which is in agreement on Lee Jung-Ting's findings [15].

IL-6 is mainly secreted by a variety of immune cells and is also highly expressed in a variety of cancer cells [48]. Our study suggested that MC38 cell lines can secrete IL-6. In vivo animal experiments showed that IL-6 in the serum of $\mathrm{Apc}^{\mathrm{Min} /+}$ mice was higher than that in the serum of WT mice at 15 weeks and 24 weeks old, respectively, which is consistent with the findings of a previous study [11]. IL-6 mRNA levels in intestinal tumors were increased compared with those in normal intestinal epithelial tissue, which echoes the data of increased serum IL-6 in clinical cancer patients [49]. The cytokines secreted by MC38 cells certainly also include MCP1 and $\mathrm{KC}$, which can recruit macrophages [50-52]. However, our experiments have shown that increased MCP1 mRNA levels was only found in intestinal tumors (Fig. $\mathrm{S} 5 \mathrm{~A}$ ) but not in the serum of $\mathrm{Apc}^{\mathrm{Min} /+}$ mice at the CAC stage (15 - 24weeks) (Fig. S5B). There was no difference in serum KC ((Fig. S5E) (Fig. S5D) and KC mRNA levels(Fig. S5C) in late-stage tumors in mice. Similarly, in clinical studies, serum $\mathrm{KC}$ did not differ between normal healthy individuals and patients with colorectal cancer (Fig. S5E). So MCP1 and KC were not being explored more in our study.

As known that knocking out IL-6 could reduce muscle consumption in $\mathrm{Apc}^{\mathrm{Min} /+}$ mice [11]. The crosstalk between tumors and inflammatory cytokines is also well known [22, 29]. Here the results show that IL-6 would induce macrophage secreting MMP12. However, the limitation of our preliminary work is that the relationship between tumor-derived IL- 6 and macrophage MMP12 has not been well explored. It is very important to specifically inhibit MMP12 in $\mathrm{Apc}^{\mathrm{Min} /+}$ mice to reduce weight loss, Another, we did not explore if other cytokines were secreted by tumors or macrophages, which would have effect on MMP12 secretion by. This should be done more in that point.

We used fluorescence electrospray ionization mass spectrometry methods to confirm that insulin and IGF-1 were degraded by MMP12, but the specific sites of amino acids in insulin and IGF-1 have not been explored. MMP12 degrades insulin in our study, which is supported by the findings of a previous study [17]. Our data and other study indicated that MMP12 was closely related to glucose and lipid metabolism, resulting in loss of skeletal muscle and adipose tissue [40-44]. Taken together, results suggest that MMP12 is closely related to glucose metabolism in $\mathrm{Apc}^{\mathrm{Min} /+}$ mice. We think that knocking out MMP12 in Apc ${ }^{\mathrm{Min} /+}$ mice may lead to partly insulin degradation, and affect insulin sensitivity and the balance of glucose utilization induced by tumor growth. Four kinds of mice blood lipid levels also showed that when had MMP12 knock out in Apc ${ }^{\mathrm{Min} /+}$ mice, total triglycerides were decreased in the early and middle stages, and high density lipoprotein cholesterol was increased in all age groups, while total cholesterol and low density lipoprotein cholesterol did not change among the 4 groups shown in Fig. S6I-L.

One question is that if knockout MMP12 would reverse muscle loss under condition of cachexia. Previous Study showed that long-term treatments with high-dose IL-6 may cause additional side effects, such as exacerbating CAC which will result in more muscle loss [53]. Here we find that MMP12, a downstream factor of IL-6, MMP12 inhibitor could significantly suppress weight loss in mice, although such effect was not enhanced after combined treatment with 5-FU (chemotherapy drug). Our study provides a new insight for the clinical treatment of cancer cachexia.

\section{Conclusions}

MMP12 may play a positive role in the process of glucose metabolism, lipid metabolism and cancer-induced cachectic muscle loss. To our knowledge, this is the first study to investigate the effect of glucose and lipid metabolism on body weight in $\mathrm{Apc}^{\mathrm{Min} /+}$; MMP12 knockout mice, establishing a relationship between tumor cell-derived IL- 6 and MMP12 of macrophages. To sum up, our study 
demonstrate that knocking out MMP12 in $\mathrm{Apc}^{\mathrm{Min} /+}$ mice significantly reduced muscle loss. There is a correlation between tumor-derived IL- 6 and macrophage MMP12 in colorectal cancer. MMP12 can degrade insulin and IGF-1, MMP12 knockout has a great impact on glucose metabolism and lipid metabolism. Therefore, inhibiting MMP12 may represent a new potential target for the clinical treatment of cancer patients with weight loss.

\section{Abbreviations}

MMP12: Matrix Metalloproteinases 12; CAC: Cancer Cachexia; Apc Min/+; MMP12-- $:$ Apc Min/+; MMP12 knockout mice; iWAT: Inguinal White Adipose Tissue; BAT: Brown Adipose Tissue (interscapular); HRP: Horseradish Peroxides; H\&E: Hematoxylin \& Eosin; qPCR: Quantitative Polymerase Chain Reaction; IHC: Immunohistochemistry; IF: Immunofluorescence; PBS: Phosphate Buffered Saline; MCP1(CCL2): Monocyte Chemoattractant Protein 1; KC(CXCL1): Keratinocyte-derived Chemokine; RANTES: Regulated upon Activation, Normal T Cell Expressed and Presumably Secreted; IL-6: Interleukin 6; IGF-1: Insulin-like Growth Factor 1.

\section{Supplementary Information}

The online version contains supplementary material available at https://doi. org/10.1186/s12885-021-09004-y.

\section{Additional file 1.}

Additional file 2 .

\section{Acknowledgements}

We thank technician Dr. Hao Chen for his help in clinical sample collection. We appreciate that Prof. Ming Li's good advices for this study. We would also like to thank Jingzhou Xie, Lixun Huang, Yongjia Zheng, Yiting Zhang, Junwei Ye, Qianhui Ma, Jiena Liu and Xiaoyang Chen for their help with the animal experiments.

\section{Authors' contributions}

Conceptualization: LJC, WL, JLB; Methodology: LC, WLJ, JLB; Software: JLB; Validation: JLB, YMM, NT; Formal analysis: LJC, JLB; Investigation: LC, JLB; Resources: LZY, WLL, LHB, NT, HMZ, HPZ; Data curation: JLB, LJC; Writing original draft preparation: JLB, LJC; Writing - review \& editing; LC, WLJ, MY, ZRX, XDH, MY; Supervision; JLB, WL; Project administration; JLB, HSH, LZY, HXD; Funding acquisition; LJC, WLJ, ZRX. All authors read and approved the final manuscript.

\section{Funding}

This work was supported by grants from the National Natural Science Foundation of China (Grant ID:81773118 to Jiangchao Li, and 31771578 to Lijing Wang). These funds support most experiments such as cells, molecules, and animals. The fund of the Key-Area Research and development Program of Guangdong Province (2019B020234003) is used for experimental consumables and drug tests.

\section{Availability of data and materials}

The related data and material in the section of my manuscript is available. When reasonably requested, the data set used and/or analyzed in the current study can be obtained from the author. The data sets supporting the results of this article are included within the article and its additional files.

\section{Declarations}

\section{Ethics approval and consent to participate}

All research had been performed in accordance with the Declaration of Helsinki. All mouse experimental protocols were approved by the animal experimental ethics committee of Guangdong Pharmaceutical University. The animal ethics approval number was gdpulac2019019. All tests were carried out with the approval of the Guangdong Medical Laboratory Animal Center, Guangzhou, China. All experiments for clinical patients in this study were obtained by the approval of the Guangzhou Human Research Ethics Committee, The First Affiliated Hospital of Guangdong Pharmaceutical University, China. The clinical ethics approval number was EC-AF-019. This study was obtained from all participants.

\section{Consent for publication \\ Not applicable.}

\section{Competing interests}

The authors declare that they have no competing interests.

\section{Author details}

${ }^{1}$ Institute of Basic Medical Sciences, School of Life Sciences and Biopharmaceuticals, Guangdong Pharmaceutical University, No. 280 Waihuan Rd. E, Higher Education Mega Center, Guangzhou 510006, China. ${ }^{2}$ The State Key Laboratory of Oncology in South China, Sun Yat-sen University Cancer Center, Guangzhou 510060, China. ${ }^{3}$ The Sixth Affiliated Hospital, Sun Yat-sen University, Guangzhou 510060, China. ${ }^{4}$ Guangdong Province Key Laboratory for Biotechnology Drug Candidates, Guangdong Pharmaceutical University, Guangzhou 510006, China.

Received: 5 May 2021 Accepted: 13 November 2021

Published online: 04 December 2021

\section{References}

1. Brody H. Colorectal cancer. Nature. 2015;521(7551):S1.

2. Lin JS, et al. Screening for colorectal Cancer: updated evidence report and systematic review for the US preventive services task force. JAMA. 2016;315(23):2576-94.

3. Siegel R, Desantis C, Jemal A. Colorectal cancer statistics, 2014. CA Cancer J Clin. 2014;64(2):104-17.

4. Bray F, et al. Global cancer statistics 2018: GLOBOCAN estimates of incidence and mortality worldwide for 36 cancers in 185 countries. CA Cancer J Clin. 2018;68(6):394-424.

5. Kasprzak A. The role of tumor microenvironment cells in colorectal Cancer (CRC) Cachexia. Int J Mol Sci. 2021;22(4):1565.

6. Baracos VE, et al. Cancer-associated cachexia. Nat Rev Dis Primers. 2018;4(1):17105.

7. Tisdale, Michael J, et al. Nat Rev Cancer. 2002;2(11):862-71.

8. Herremans KM, Riner AN, Cameron ME. Trevino JGThe microbiota and Cancer Cachexia. Int J Mol Sci. 2019;20(24):6267.

9. Center MM, et al. Worldwide variations in colorectal cancer. CA Cancer J Clin. 2009;59(6):366-78.

10. Johdi NA, Sukor NF. Colorectal Cancer immunotherapy: options and strategies. Front Immunol. 2020;11:1624.

11. Baltgalvis KA, et al. Interleukin-6 and cachexia in ApcMin/+ mice. Am J Physiol Regul Integr Comp Physiol. 2008;294(2):R393-401.

12. White JP, et al. The regulation of skeletal muscle protein turnover during the progression of cancer cachexia in the Apc $(\mathrm{min} /+)$ mouse. PLoS One. 2011;6(9):e24650

13. Bauters D, Van Hul M, Lijnen HR. Macrophage elastase (MMP12) in expanding murine adipose tissue. Biochim Biophys Acta. 2013;1830(4):2954-9.

14. Han J, et al. Interleukin-6 induces fat loss in cancer cachexia by promoting white adipose tissue lipolysis and browning. Lipids Health Dis. 2018:17(1):14

15. Lee JT, et al. Macrophage metalloelastase (MMP12) regulates adipose tissue expansion, insulin sensitivity, and expression of inducible nitric oxide synthase. Endocrinology. 2014;155(9):3409-20.

16. Hotary KB, et al. Membrane type I matrix metalloproteinase usurps tumor growth control imposed by the three-dimensional extracellular matrix. Cell. 2003;114(1):33-45.

17. Kettner $C$, et al. The specificity of macrophage elastase on the insulin B-chain. Biochem J. 1981;195(2):369-72. 
18. Amor M, et al. Identification of matrix metalloproteinase-12 as a candidate molecule for prevention and treatment of cardiometabolic disease. Mol Med. 2016;22:487-96.

19. Asp ML, et al. Evidence for the contribution of insulin resistance to the development of cachexia in tumor-bearing mice. Int J Cancer. 2010;126(3):756-63.

20. Pettersen $\mathrm{K}$, et al. Cancer cachexia associates with a systemic autophagyinducing activity mimicked by cancer cell-derived IL-6 trans-signaling. Sci Rep. 2017;7(1):2046

21. Yarla NS, Polito A, Peluso I. Effects of olive oil on TNF-a and IL-6 in humans: implication in obesity and frailty. Endocr Metab Immune Disord Drug Targets. 2018;18(1):63-74.

22. Talbert EE, et al. Circulating monocyte chemoattractant protein-1 (MCP-1) is associated with cachexia in treatment-naïve pancreatic cancer patients. J Cachexia Sarcopenia Muscle. 2018;9(2):358-68.

23. Bing C. Lipid mobilization in cachexia: mechanisms and mediators. Curr Opin Support Palliat Care. 2011;5(4):356-60.

24. Baracos VE, Mazurak VC, Bhullar AS. Cancer cachexia is defined by an ongoing loss of skeletal muscle mass. Ann Palliat Med. 2019;8(1):3-12.

25. Webster JM, et al. Inflammation and skeletal muscle wasting during Cachexia. Front Physiol. 2020;11:597675.

26. Carson JA, Baltgalvis KA. Interleukin 6 as a key regulator of muscle mass during cachexia. Exerc Sport Sci Rev. 2010;38(4):168-76.

27. Utsumi K, Takai Y, Tada T, Ohzeki S, Fujiwara H, Hamaoka T. Enhanced production of IL-6 in tumor-bearing mice and determination of cells responsible for its augmented production. J Immunol. 1990;145(1):397_ 403. PMID: 1972720

28. Chevalier S, Farsijani S. Cancer cachexia and diabetes: similarities in metabolic alterations and possible treatment. Appl Physiol Nutr Metab. 2014;39(6):643-53.

29. Zhang $Y$, et al. Sophocarpine and matrine inhibit the production of TNF-alpha and IL-6 in murine macrophages and prevent cachexia-related symptoms induced by colon26 adenocarcinoma in mice. Int Immunopharmacol. 2008;8(13-14):1767-72.

30. Peixoto da Silva S, et al. Cancer cachexia and its pathophysiology: links with sarcopenia, anorexia and asthenia. J Cachexia Sarcopenia Muscle. 2020;11(3):619-35.

31. Deshmukh AS. Insulin-stimulated glucose uptake in healthy and insulinresistant skeletal muscle. Horm Mol Biol Clin Investig. 2016;26(1):13-24.

32. Nicholson T, Church C, Tsintzas K, Jones R, Breen L, Davis ET, Baker DJ, Jones SW. Vaspin promotes insulin sensitivity of elderly muscle and is upregulated in obesity. J Endocrinol. 2019:JOE-18-0528.R3.

33. Li W, et al. A selective matrix metalloprotease 12 inhibitor for potential treatment of chronic obstructive pulmonary disease (COPD): discovery of (S)-2-(8-(methoxycarbonylamino)dibenzo[b,d]furan-3-sulfonamido)3-methylbutanoic acid (MMP408). J Med Chem. 2009;52(7):1799-802.

34. Li J, et al. Macrophage metalloelastase (MMP-12) deficiency mitigates retinal inflammation and pathological angiogenesis in ischemic retinopathy. PLoS One. 2012;7(12):e52699.

35. Atlı Ö, Ilgın S, Ergun B, Burukoğlu D, Musmul A, Sırmagül B. Matrix metalloproteinases are possible targets in monocrotaline-induced pulmonary hypertension: investigation of anti-remodeling effects of alagebrium and everolimus. Anatol J Cardiol. 2017;17(1):8-17.

36. Li J, et al. Targeting Interleukin-6 (IL-6) sensitizes anti-PD-L1 treatment in a colorectal Cancer preclinical model. Med Sci Monit. 2018;24:5501-8.

37. Franckhauser $\mathrm{S}$, et al. Overexpression of $\| 6$ leads to hyperinsulinaemia, liver inflammation and reduced body weight in mice. Diabetologia. 2008;51(7):1306-16.

38. Suzuki K, et al. Roles of alternatively activated M2 macrophages in allergic contact dermatitis. Allergol Int. 2017;66(3):392-7.

39. Wang $Q$, et al. Vascular niche IL-6 induces alternative macrophage activation in glioblastoma through HIF-2a. Nat Commun. 2018;9(1):559.

40. Han X, et al. Mechanisms involved in follistatin-induced hypertrophy and increased insulin action in skeletal muscle. J Cachexia Sarcopenia Muscle. 2019;10(6):1241-57.

41. Baker Rogers J, Syed K, Minteer JF. Cachexia, in StatPearls. Treasure Island: (c) 2020, StatPearls Publishing LLC; 2020.

42. Masi T, Patel BM. Altered glucose metabolism and insulin resistance in cancer-induced cachexia: a sweet poison. Pharmacol Rep. 2021;73(1):17-30
43. Takayama K. Overview of Cancer-associated Cachexia. Gan To Kagaku Ryoho. 2019;46(12):1814-7.

44. Dev R, Del Fabbro E, Dalal S. Endocrinopathies and cancer cachexia. Curr Opin Support Palliat Care. 2019;13(4):286-91.

45. Masi T, Patel BM. Altered glucose metabolism and insulin resistance in cancer-induced cachexia: a sweet poison. Pharmacol Rep. 2021;73(1):17-30

46. van der Werf A, et al. Cancer Cachexia: identification by clinical assessment versus international consensus criteria in patients with metastatic colorectal Cancer. Nutr Cancer. 2018;70(8):1322-9.

47. Yang $\mathrm{M}$, et al. Knocking out matrix metalloproteinase 12 causes the accumulation of M2 macrophages in intestinal tumor microenvironment of mice. Cancer Immunol Immunother. 2020;69(8):1409-21.

48. Mauer J, Denson JL, Brüning JC. Versatile functions for IL-6 in metabolism and cancer. Trends Immunol. 2015;36(2):92-101.

49. Nikiteas NI, et al. Serum IL-6, TNFa and CRP levels in Greek colorectal cancer patients: prognostic implications. World J Gastroenterol. 2005;11(011):1639-43.

50. Engin AB. Adipocyte-macrophage cross-talk in obesity. Adv Exp Med Biol. 2017;960:327-43.

51. Wang $M$, et al. A local proinflammatory signalling loop facilitates adverse age-associated arterial remodeling. PLoS One. 2011;6(2):e16653.

52. Barcelos LS, et al. Production and in vivo effects of chemokines CXCL1-3/ $\mathrm{KC}$ and CCL2/JE in a model of inflammatory angiogenesis in mice. Inflamm Res. 2004;53(10):576-84.

53. Wada E, et al. Treatment with the anti-IL-6 receptor antibody attenuates muscular dystrophy via promoting skeletal muscle regeneration in dystrophin-/utrophin-deficient mice. Skelet Muscle. 2017;7(1):23.

\section{Publisher's Note}

Springer Nature remains neutral with regard to jurisdictional claims in published maps and institutional affiliations.
Ready to submit your research? Choose BMC and benefit from:

- fast, convenient online submission

- thorough peer review by experienced researchers in your field

- rapid publication on acceptance

- support for research data, including large and complex data types

- gold Open Access which fosters wider collaboration and increased citations

- maximum visibility for your research: over $100 \mathrm{M}$ website views per year

At BMC, research is always in progress.

Learn more biomedcentral.com/submissions 